Ping Xu $\cdot$ Huawu Liu

\title{
Models of microfibril elastic modulus parallel to the cell axis
}

Published online: 1 September 2004

(C) Springer-Verlag 2004

\section{Wood Sci Technol (2004) 38: 363-374}

The address of the second author is as follows:

Canesis Network Ltd., Private Bag 4749, Christchurch, New Zealand

On page 367 Eq. 3 should read:

$$
[T]=\left[\begin{array}{cccccc}
c^{2} & s^{2} & 0 & 0 & 0 & 2 s c \\
s^{2} & c^{2} & 0 & 0 & 0 & -2 s c \\
0 & 0 & 1 & 0 & 0 & 0 \\
0 & 0 & 0 & c & -s & 0 \\
0 & 0 & 0 & s & c & 0 \\
-s c & s c & 0 & 0 & 0 & c^{2}-s^{2}
\end{array}\right] \quad c=\cos (-\theta), s=\sin (-\theta)
$$

On page 368 Eq. 12 should read:

$$
[\bar{C}]\left\{\varepsilon_{\mathrm{c} 1}\right\}=[\bar{C}][\bar{S}]\left\{\sigma_{\mathrm{c} 1}\right\}=\left\{\sigma_{\mathrm{cl}}\right\}
$$

On page 370 in line 10 the subscript of the symbol $A$ should be f, so it should read: Denoting...... $A_{\mathrm{f}} \ldots .$.

On page $371 \mathrm{Eq} .28$ should read:

$\bar{E}_{\mathrm{f}}(\theta)=E_{l}\left(\cos ^{2} \theta-v_{12} \sin ^{2} \theta\right) \cos ^{2} \theta$

On page $371 \mathrm{Eq} .29$ should read:

$\bar{E}_{\mathrm{f}}(\theta)=E_{l} \cos ^{4} \theta$

The online version of the original article can be found at http://dx.doi.org/10.1007/s00226-004-0235-7

P. Xu ( $\square)$

Forest Research, Forestry Road, University of Canterbury,

PO Box 29 237, Fendalton, Christchurch, New Zealand

E-mail: ping.xu@forestresearch.co.nz

H. Liu

Canesis Network Ltd., Private Bag 4749, Christchurch,

New Zealand 